\title{
TEAM-TEACHING IN AN INTEGRATED FRESHMAN ENGINEERING CURRICULUM
}

\author{
Richard M. Felder, Leonhard E. Bernold, Ernest E. Burniston, \\ Philip R. Dail, John E. Gastineau \\ North Carolina State University
}

An integrated freshman engineering curriculum called IMPEC (for Integrated Mathematics, Physics, Engineering, and Chemistry Curriculum) is currently being pilot-tested at North Carolina State University under the sponsorship of the NSF SUCCEED Coalition. In each semester, the students take a calculus course, a science course (chemistry in the first semester, physics in the second), and a one-credit engineering course. The goals of the curriculum are to provide (1) motivation and context for the fundamental material taught in the first-year mathematics and science courses; (2) a realistic and positive orientation to the engineering profession, and (3) training in the problem-solving, study, and communication skills that correlate with success in engineering school and equip individuals to be lifelong learners.

IMPEC is one of a number of integrated engineering curricula being developed around the country. In contrast to many of the other programs in which courses in different disciplines are simply coordinated, IMPEC features full integration. The curriculum is taught by a multidisciplinary team of professors using a combination of traditional lecturing and alternative instructional methods including cooperative learning, activity-based class sessions, and extensive use of computer simulations. A single computer-equipped classroom that accommodates 36 students serves for all class meetings (except for chemistry wet-labs). This paper outlines the approach used to develop and teach the curriculum and proposes necessary conditions for multidisciplinary team teaching to be effective.

\section{Faculty Roles and Tasks}

One faculty member (RMF) serves as overall project coordinator and instructor in the first-semester engineering course. Another (JEG), who is fully supported by the project funding, takes principal responsibility for student recruitment and program logistics (class scheduling, equipment and supplies maintenance, and coordination of assignment and handout preparation) and is also the physics instructor. Both of these faculty members jointly coordinate the program assessment and evaluation. The remaining faculty members have teaching as their primary responsibility: calculus (EEB), chemistry (PRD), and the second- semester engineering course (LEB).

All project faculty members participate in the summer orientation session. The coordinator describes the overall program objectives, structure, and instructional approach, each faculty member describes the role of his discipline in the curriculum, and everyone responds to questions. At the end of the session, students interested in participating sign forms that give us permission to access their records for program assessment purposes. One of us (JEG) selects the 36 students who will participate, matching the demographic profile of the class to that of the overall freshman engineering class, and assigns other would-be participants to a control group whose performance will be compared with that of the IMPEC group. 
During the academic year, we meet for an average of an hour each week to review the previous week's progress, plan the homework assignments and class activities for the coming week, and discuss any existing or anticipated difficulties with the classes or with individual students. We also regularly lay out class schedules for the next few weeks. Blocks of time are nominally allocated to each subject, but for both curricular reasons (e.g., material in calculus needs to precede related material in physics) and personal reasons (e.g., one of us will be out of town attending a conference) we often rearrange the schedule.

Calculus, chemistry, and physics homework assignments, pre-test study guides, and tests are generally planned 1-2 weeks in advance. The calculus and science instructors prepare drafts, and the engineering instructor reviews them and sometimes inserts additional problems designed to integrate the subjects within a realistic engineering context. Fortunately, the textbooks we use are rich in applied problems, so we do not have to make up that many of our own. The project coordinator prepares drafts of mid-semester and final course evaluation forms for the students to complete, and the rest of the project faculty reviews and modifies the forms. Routine examination of draft materials by several faculty team members is time-consuming, but contributes significantly to the desired mixing of disciplines in the final products.

\section{Program Assessment and Evaluation}

A variety of measures is being used to evaluate IMPEC, including grades on standardized tests and in selected courses, data on retention in engineering, and responses on attitude surveys. Data are being collected for IMPEC students, a control group, and various comparison groups. The results of our preliminary assessments indicate that IMPEC is meeting all of the objectives stated in the introduction to this paper with a high degree of success. Whether the program can be successfully scaled up from its current level of 36 students to a sizable fraction of the roughly 1100 freshman engineering students at N.C. State University is still an open question.

\section{Necessary Conditions for Successful Team Teaching in an Integrated Curriculum}

Curriculum integration requires changing the content (to some extent) and the mode of presentation (considerably) of traditional courses. Coordinated planning of class sessions, assignments, and tests is crucial. In IMPEC, we had to adjust to these challenges, and in addition the engineering instructors had to learn to teach freshmen. The experience has been occasionally frustrating but generally enjoyable for all of us-less frustrating and more enjoyable in the second year of the program, now that we have some idea of what we're doing. We don't have a complete recipe for how to do multidisciplinary team teaching successfully, since we're still working it out for ourselves, but we can list several factors that have contributed to IMPEC's success so far.

- Adequate incentives and support for program faculty. The need to adjust our teaching to meet the requirements of the curriculum imposed a considerable drain on our time and energy. We had the incentive of external support through a SUCCEED Coalition grant, which provided us with release time, summer salary, travel funds, and the other perquisites that go with funded research. If programs like IMPEC are to be institutionalized, the considerable time demands on participating faculty members should be considered by their administrators when their workloads are evaluated, especially in the first few years of the programs. 
- Compatible faculty members. We did not all know each other before IMPEC, and only two of us had ever worked together prior to IMPEC. Fortuitously, without exception we respect each other professionally and like each other personally. We suppose it might be possible to team-teach successfully in the absence of the second condition, but it is hard to imagine doing so for very long, and we cannot imagine a successful experience without complete mutual respect and trust among the participating faculty.

- A faculty team that understands and subscribes to the program's philosophy and goals, believes in its potential benefits, and can sell it to the students and to appropriate university administrators. A program like IMPEC comes with a number of built-in obstacles, ranging from student resistance to unaccustomed demands (like not having course material neatly compartmentalized and having to work in teams) to administrative resistance to the cost and complexity of multidisciplinary programs. Even a single unenthusiastic faculty team member could be enough to sabotage a program.

- $\quad$ Patience, flexibility, and constant communication, especially during the initial program development. There is always a learning curve associated with innovative instructional programs, both for the students and for the faculty. In the first year of the program, we constantly had to adjust class schedules, rearrange course content, adjust the length and difficulty of the assignments, and deal with an impressive variety of student-related problems. Largely because of our weekly meetings, we were able to make the necessary adjustments; the level of chaos would have ensued if we had attempted to hold fast to a preset game plan is unimaginable. The second year is going far more smoothly, but the need for patience and flexibility is still prominent.

In summary, the problems associated with multidisciplinary team-teaching in an integrated program are considerable but far from insurmountable. In our opinion, the ultimate educational benefits to the students more than justify the required effort. 


\section{Acknowledgments}

IMPEC is supported by the National Science Foundation SUCCEED Coalition. We are indebted to John Risley for his contributions to program planning and to Ben O'Neal for his teaching effort in the first year of the program.

RICHARD M. FELDER is Hoechst Celanese Professor of Chemical Engineering at N.C. State University. He coordinates the IMPEC project and teaches the fall engineering course.

LEONHARD E. BERNOLD is Associate Professor of Civil Engineering at N.C. State University. He teaches the spring IMPEC engineering course.

ERNEST E. BURNISTON is Professor of Mathematics at N.C. State University. He teaches the fall and spring IMPEC calculus courses.

PHILIP R. DAIL is an academic advisor and chemistry instructor with the First-Year College at N.C. State University. He teaches the IMPEC chemistry course.

JOHN E. GASTINEAU is a Visiting Associate Professor of Physics at N.C. State University. He teaches the IMPEC physics course and coordinates course enrollment, equipment acquisition and maintenance, and program assessment and evaluation. 